\title{
Genetic polymorphisms in warfarin and tacrolimus-related genes VKORC1, CYP2C9 and CYP3A5 in the Greek-Cypriot population
}

Despina Hadjipanagi, Stephanie Chrysanthou, Konstantinos Voskarides ${ }^{*}$ and Constantinos Deltas*

\begin{abstract}
Background: Two variants in the gene encoding the cytochrome P450 2C9 enzyme (CYP2C9) are considered the most significant genetic risk factors associated with bleeding after warfarin prescription. A variant in the vitamin $\mathrm{K}$ epoxide reductase (VKORC1) has been also associated by several studies with warfarin response. Another variant in the P450 3A5 enzyme (CYP3A5) gene is known to affect the metabolism of many drugs, including tacrolimus.

Findings: We conducted a population genetic study in 148 unrelated healthy Greek-Cypriot volunteers (through PCR-RFLP assays), in order to determine the frequencies of the above pharmacogenetics variants and to compare allele frequencies with those in other major ethnic groups. The allele frequencies of CYP2C9*2, CYP2C $9^{*} 3$ and CYP3A5*3 were found to be $0.162,0.112$ and 0.943 respectively, whereas VKORC1 - 1639A was 0.534 . The latter frequency differs significantly when compared with Caucasians, Asians and Africans $(p<0.001)$ and is still significant when compared with the geographically and culturally closely related to Greek-Cypriots, Hellenes of Greece $(p=0.01)$. Interestingly $\sim 18 \%$ of our population are carriers of four or three risk alleles regarding warfarin sensitivity, therefore they have a high predisposition for bleeding after taking high or even normal warfarin doses.
\end{abstract}

Conclusions: Our data show no significant difference in the frequency of CYP2C9 and CYP3A5 allelic variants when compared to the Caucasian population, but differ significantly when compared with Africans and Asians $(p<0.001)$. Also, the frequency of variant VKORC1 - 1639A differs between Greek-Cypriots and every other population we compared. Finally, about 1/5 Greek-Cypriots carry three or four risk alleles and 50\% of them carry at least two independent risk alleles regarding warfarin sensitivity, a potentially high risk for over-anticoagulation.

Keywords: CYP2C9, CYP3A5, VKORC1, Cyprus, Greek-Cypriots, Pharmacogenetics, Population genetics

\section{Findings}

\section{Background}

There are genetic variations in genes encoding for the hepatic CYP450 metabolizing enzymes that can lead to undesirable drug reactions or inadequate response to commonly prescribed doses, either because of reduced or enhanced enzyme activity, respectively [1]. Testing for the activity of the CYP450 enzymes and isoforms before a patient receives a specific medication can provide valuable information concerning the initial dose. Molecular genetic testing is advantageous and more cost-

\footnotetext{
*Correspondence: kvoskar@ucy.ac.cy; Deltas@ucy.ac.cy

Molecular Medicine Research Center and Laboratory of Molecular and Medical Genetics, Department of Biological Sciences, University of Cyprus, Nicosia, Cyprus
}

\section{Biomed Central

effective compared to enzymatic methods due to methodological simplicity.

It is notable that in August 2007, the FDA label for warfarin, a frequently used anti-coagulant drug, was updated to highlight the benefit of genetic testing to predict warfarin response. This was renewed on February 2010 (http://www.fda.gov/). Candidate-gene association studies have identified two genes responsible for the main proportion of warfarin response: $C Y P 2 C 9$, which codes for the enzyme cytochrome CYP450 2C9 that metabolizes S-warfarin [2] and VKORC1, which codes for warfarin's target, vitamin $\mathrm{K}$ epoxide reductase [3]. CYP2C9*2 (Arg 144 to Cys) and CYP2C9*3 (Ile 359 to Leu) are recognized as the main $C Y P 2 C 9$ variants in humans, affecting negatively the enzyme activity $[4,5]$. In order to avoid high risk for bleeding, these polymorphisms must be taken into 
Table 1 Genotype distribution of the four pharmacogenetics variants in the Greek-Cypriot population

\begin{tabular}{|c|c|c|c|c|c|c|c|c|c|c|c|c|}
\hline \multirow[b]{2}{*}{$\mathbf{n}$} & \multicolumn{3}{|c|}{ VKORC1 -1639AG } & \multicolumn{3}{|c|}{ CYP2C9 } & \multicolumn{3}{|c|}{ CYP2C9 } & \multicolumn{3}{|c|}{ CYP3A5 } \\
\hline & $\overline{A A}$ & AG & GG & $* 1 / * 1$ & ${ }^{*} 1 / * 2$ & $* 2 / * 2$ & $* 1 / * 1$ & $* 1 / * 3$ & $* 3 / * 3$ & $* 1 / * 1$ & ${ }^{*} 1 / * 3$ & $* 3 / * 3$ \\
\hline 148 & 44 & 70 & 34 & 107 & 34 & 7 & 115 & 33 & 0 & 0 & 17 & 131 \\
\hline 100 & $29.7 \%$ & $47.3 \%$ & $23.0 \%$ & $72.3 \%$ & $23.0 \%$ & $4.7 \%$ & $77.7 \%$ & $22.3 \%$ & $0 \%$ & $0 \%$ & $11.5 \%$ & $88.5 \%$ \\
\hline
\end{tabular}

account before warfarin treatment [6]. Warfarin-dosing algorithms that incorporate CYP2C9 and VKORC1 genetic profile seem to predict pretty accurately the required warfarin dose for each patient $[7,8]$.

The CYP3A5 gene represents the major extrahepatic isoform of CYP3A gene family and in association with CYP3A4 are responsible for the metabolism of over $50 \%$ of all the clinically used drugs [9]. Some studies pay special attention at the frequent $C Y P 3 A 5 * 3$ allele and tacrolimus dosing [10], a frequently used immunosuppressant drug. It is recommended that homozygous CYP3A5*3/*3 patients receive roughly a $50 \%$ lower initial tacrolimus dose than patients with at least one wild type $C Y P 3 A 5^{*} 1$ allele as a result of the difference observed in oral clearance $[10,11]$.

According to the available bibliography, it is more than evident that different human populations can differ significantly in genetic allelic frequencies for drug metabolism genes [12]. The purpose of the present study was to investigate for the first time the prevalence of the most common allelic variants of VKORC1, CYP2C9 and CYP3A5 in a representative sample of the Greek-Cypriot population, and to compare these data with existing published data from other populations.

\section{Methods}

\section{Subjects}

Genomic DNA isolated from whole peripheral blood [13] from 148 male healthy unrelated Greek-Cypriot subjects over 20 years old, was used for this study. The population of Greek-Cypriots is 660,000 (census of 2011), therefore the number of 148 individuals represents adequately our population. The subjects were selected according to their origin, aiming at even geographical coverage of all the provinces of Cyprus, including mountainous areas, thereby avoiding population stratification. We enrolled only male subjects for this study due to the fact we had more information about their geographic origin in contrast with females, because of their participation in another phylogenetics project. The DNA samples were used after they were anonymized. Our research project has been approved by the Cyprus National Bioethics Committee. Informed consent was obtained from all subjects. Research carried out on volunteers of this study was in compliance with the Helsinki Declaration.

\section{Molecular genetic analysis}

In this study we directly tested our sample group only for the four following genetic variants: VKORC1 g.-1639G/A, CYP2C9*2, CYP2C9*3 and CYP3A5*3. We did not test specifically for the wild type CYP2C9*1 allele, the frequency of which was inferred from the absence of the two variants tested. The genetic polymorphisms were genotyped by PCR-RFLP assays. Details of the methods regarding the VKORC1 g.-1639G/A, CYP2C9*2 and CYP3A5*3 polymorphisms are described elsewhere [14-16]. For the CYP2C9*3 polymorphism, the following primers were designed and used for amplification:

\section{CYP2C9-3_For: 5' ACACAGATGCTGTGGTGCACG AGGTCCAGAGGTAC 3' \\ CYP2C9-3_Rev: 5' CTGGAAACAAGAGAAAGTCCA GTTAAACTGCCATAC 3}

The forward primer was modified by substitution of the fourth nucleotide from the 3' end, from A to G (italics and bold), so that upon amplification a restriction recognition site for BanI is created. The digestion products were analyzed by electrophoresis on $3.5 \%$ agarose gels. The CYP2C9*3 allele is represented by the $225 \mathrm{bp}$ and $31 \mathrm{bp}$

Table 2 Genotypic combinations of the three genotyped variants related with warfarin, in 148 Greek-Cypriot individuals

\begin{tabular}{|c|c|c|c|c|}
\hline \multicolumn{3}{|c|}{ Genotypic combinations } & \multirow{2}{*}{$\begin{array}{l}\text { No } \\
0\end{array}$} & \multirow{2}{*}{$\begin{array}{l}\% \\
0\end{array}$} \\
\hline VKORC1 -AA & $\mathrm{CYP} 2 \mathrm{CO}^{*} 2 /{ }^{*} 2$ & CYP2C9*1/*3 & & \\
\hline VKORC1 -AA & $\mathrm{CYP} 2 \mathrm{CO}^{*} 2 /{ }^{*} 2$ & CYP2C9*1/*1 & $2 * * * *$ & 1.35 \\
\hline VKORC1 -AA & CYP2CO*1/*2 & CYP2C9*1/*3 & $2 * * * *$ & 1.35 \\
\hline VKORC1 -AG & $C Y P 2 C 9^{*} 1 / * 2$ & CYP2C9*1/*3 & $2 * * *$ & 1.35 \\
\hline VKORC1 -AG & CYP2CO*2/*2 & CYP2C9*1/*1 & $3^{* * *}$ & 2.03 \\
\hline VKORC1 -AA & CYP2CO*1/*2 & $\operatorname{CYP} 29^{*} 1 /{ }^{*} 1$ & $7 * * *$ & 4.73 \\
\hline VKORC1 -AA & CYP2CO*1/*1 & CYP2C9*1/*3 & $10 * * *$ & 6.76 \\
\hline$\overline{V K O R C 1-A G+G G}$ & $\mathrm{CYP} 2 \mathrm{CO}^{*} 1 /{ }^{* 1}$ & $\operatorname{CYP} 2 \mathrm{Cg}^{*} 1 /{ }^{*} 3$ & 19 & 12.84 \\
\hline VKORC1 -AA & $\mathrm{CYP} 2 \mathrm{CO}^{*} 1 /{ }^{* 1}$ & $\operatorname{CYP} 29^{*} 1 / * 1$ & 23 & 15.54 \\
\hline VKORC1 -AG + GG & CYP2C9* $1 /{ }^{*} 2+{ }^{*} 2 /{ }^{*} 2$ & CYP2C9*1/*1 & 25 & 16.89 \\
\hline VKORC1 - $A G+G G$ & $\mathrm{CYP} 2 \mathrm{CO}^{*} 1 /{ }^{* 1}$ & $\operatorname{CYP} 29^{*} 1 / * 1$ & 55 & 37.16 \\
\hline SUM & & & 148 & 100 \\
\hline
\end{tabular}

No CYP2C $9 * 3{ }^{*} 3$ genotypes were observed.

****Individuals with four risk alleles $(2.70 \%)$.

***Individuals with three risk alleles (14.87\%). 
bands, whereas wild type allele is represented by the uncut 256 bp band.

\section{Statistical analysis}

Comparison of population allele frequencies was performed through Pearson chi-square test, using SPSSv.15 statistical package (IBM, USA). The significance level, alpha, was set to 0.05 . Hardy-Weinberg equilibrium was tested for all the analyzed polymorphisms through an Excel based application (Microsoft Office 2007).

\section{Results and discussion}

Genotypic frequencies for the tested pharmacogenetics variants in our population are tabulated in Table 1 . The genotypic frequencies for each variant are in HardyWeinberg equilibrium. All the tested Greek-Cypriots are carriers of the $C Y P 3 A 5^{*} 3$ allele (no homozygous wildtype CYP3A5*1/*1 were found), which is responsible for reduced tacrolimus clearance, while $88.5 \%$ of them are homozygous CYP3A5*3/*3 (Table 1). These frequencies are very similar with those for the Hellenic population in Greece and generally with those for the Caucasian population [12,17]. We paid special attention at genotypic combinations for the three genotyped warfarin related genes (Table 2). We believe that clinicians in Cyprus have to take seriously into account that $\sim 18 \%$ of the GreekCypriot population they serve are carriers of four or three risk alleles and about 50\% carry at least two risk alleles, predisposing for bleeding after taking high warfarin doses. The combinatorial frequency of CYP2C9 and VKORC1 genotypes in the target population appears higher than expected based on individual genotypes, but we do not have

Table 3 Allele frequencies of the four studied pharmacogenetic variants in Cyprus and comparison with other populations

\begin{tabular}{|c|c|c|c|c|c|c|}
\hline Population group & No of tested chromosomes & VKORC1 -1639A & $C Y P 2 C 9 * 2$ & CYP2C9*3 & CYP $3 A 5 * 3$ & Reference \\
\hline Greek-Cypriots & 296 & $53.38 \%$ & $16.20 \%$ & $11.15 \%$ & $94.26 \%$ & This study \\
\hline Nicosia & 106 & $62.26 \%$ & $18.87 \%$ & $9.43 \%$ & $95.28 \%$ & \\
\hline Limassol & 52 & $44.23 \%$ & $19.23 \%$ & $11.54 \%$ & $96.15 \%$ & \\
\hline Ammochostos & 60 & $51.67 \%$ & $15.00 \%$ & $15.00 \%$ & $93.33 \%$ & \\
\hline Larnaka & 28 & $50.00 \%$ & $14.29 \%$ & $7.14 \%$ & $92.86 \%$ & \\
\hline Pafos & 32 & $50.00 \%$ & $9.38 \%$ & $9.38 \%$ & $90.63 \%$ & \\
\hline Kerynia & 18 & $44.44 \%$ & $11.11 \%$ & $16.67 \%$ & $94.44 \%$ & \\
\hline \multirow[t]{6}{*}{ Caucasians } & 1362 & $37.81 \%$ & & & & [21] \\
\hline & & $(P<0.001)$ & & & & \\
\hline & 3484 & & $14.00 \%$ & $6.40 \%$ & & {$[12]$} \\
\hline & & & $(P=0.296)$ & $(P=0.002)$ & & \\
\hline & 284 & & & & $95.50 \%$ & {$[12]$} \\
\hline & & & & & $(P=0.526)$ & \\
\hline \multirow[t]{6}{*}{ Africans } & 736 & $10.05 \%$ & & & & [21] \\
\hline & & $(P<0.001)$ & & & & \\
\hline & 1376 & & $2.20 \%$ & $1.80 \%$ & & [12] \\
\hline & & & $(P<0.0001)$ & $(P<0.001)$ & & \\
\hline & 1330 & & & & $31.80 \%$ & {$[12]$} \\
\hline & & & & & $(P<0.001)$ & \\
\hline \multirow[t]{6}{*}{ Eastern Asians } & 1282 & $91.03 \%$ & & & & [21] \\
\hline & & $(P<0.001)$ & & & & \\
\hline & 13284 & & $<0.1 \%$ & $3.30 \%$ & & {$[12]$} \\
\hline & & & $(P<0.001)$ & $(P<0.001)$ & & \\
\hline & 7658 & & & & $76.10 \%$ & {$[12]$} \\
\hline & & & & & $(P<0.001)$ & \\
\hline \multirow[t]{4}{*}{ Hellenes from Greece } & 656 & $44.40 \%$ & & & & [22] \\
\hline & & $(P=0.010)$ & & & & \\
\hline & 566 & & $12.90 \%$ & $8.13 \%$ & $94.35 \%$ & {$[17]$} \\
\hline & & & $(P=0.183)$ & $(P=0.144)$ & $(P=0.957)$ & \\
\hline
\end{tabular}

In parenthesis: p-value after comparison with the Greek-Cypriot frequencies. 
a convincing explanation for this. Individuals carrying six or five risk alleles were not detected. Interestingly, we found that $2.7 \%$ of subjects in our population sample are simultaneously carriers for the three tested variants (Table 2), a frequency that is exactly the same with what is reported in Jewish populations [18].

It has been proven that $C Y P 2 C 9 * 2$ and $* 3$ cause a reduction in S-warfarin clearance (10-fold variation observed from CYP2C9*11 to CYP2C9*33) activity (*1/*1 > $\left.{ }^{*} 1 / * 2>* 1 / * 3>* 2 / * 2>* 2 / * 3>* 3 / * 3\right)$. The effect of the CYP2C9*3/3 genotype is the most severe one with clearance of S-warfarin being $10 \%$ of the wild type genotype [19]. VKORC1 encoded enzyme interacts with warfarin, so the enzyme levels can affect sensitivity to warfarin. Jorgensen et al. [20], reviewed recently almost all the available bibliography and found that $C Y P 2 C 9 * 3$ and VKORC1 variants are significant for warfarin dose determination for most ethnic populations [20]. Sconce et al. [7] showed clearly (giving also a useful algorithm for warfarin dose determination) that the three significant variants of the aforementioned genes have additive properties [7].

In conclusion, it is evident through population specific studies, like the one we present here, that pharmacogenetics allele frequencies can differ significantly in different sub-populations. The results of our study compare well to those of other Caucasian populations, but with some notable differences, like the increased frequency of the VKORC1-1639A allele (Table 3). Allele frequencies between the six provinces of Cyprus show high similarity (Table 3). We must have in mind that the Greek-Cypriot population used to be isolated and small, and therefore susceptible to migratory waves and genetic drift phenomena. Even comparing with the Greek population of Greece, that we are closely related (geographically and culturally), there are still some significant differences (Table 3). This fact underlines the necessity for population-specific allelic frequency studies, since these determinations can be helpful for the prescribing clinicians and their patients.

\section{Competing interests}

The authors declare that they have no competing interests.

\section{Authors' contributions}

$\mathrm{CD}$ and $\mathrm{KV}$ conceptualized the study, collected the samples, supervised genotyping and wrote the manuscript. KV performed the statistical analysis. $\mathrm{DH}$ performed most of the genotyping of this study and she categorized the data. SC genotyped the VKORC1 variant. All authors read and approved the final manuscript.

\section{Acknowledgements}

This research project was covered from internal University of Cyprus funds to CD (Chapter 3/311).

Received: 9 May 2013 Accepted: 1 March 2014

Published: 5 March 2014

\section{References}

1. Ingelman-Sundberg M: Pharmacogenetics of cytochrome P450 and its applications in drug therapy: the past, present and future. Trends Pharmacol Sci 2004, 25:193-200.

2. Aithal GP, Day CP, Kesteven PJ, Daly AK: Association of polymorphisms in the cytochrome P450 CYP2C9 with warfarin dose requirement and risk of bleeding complications. Lancet 1999, 353:717-719.

3. Yuan HY, Chen JJ, Lee MT, Wung JC, Chen YF, Charng MJ, Lu MJ, Hung CR, Wei CY, Chen CH, Wu JY, Chen YT: A novel functional VKORC1 promoter polymorphism is associated with inter-individual and inter-ethnic differences in warfarin sensitivity. Hum Mol Genet 2005, 14:1745-1751.

4. Lee CR, Goldstein JA, Pieper JA: Cytochrome P450 2C9 polymorphisms: a comprehensive review of the in-vitro and human data. Pharmacogenetics 2002, 12:251-263.

5. Miners JO, Birkett DJ: Cytochrome P4502C9: an enzyme of major importance in human drug metabolism. Br J Clin Pharmacol 1998, 45:525-538.

6. Higashi MK, Veenstra DL, Kondo LM, Wittkowsky AK, Srinouanprachanh SL, Farin FM, Rettie AE: Association between CYP2C9 genetic variants and anticoagulation-related outcomes during warfarin therapy. JAMA 2002, 287:1690-1698.

7. Sconce EA, Khan TI, Wynne HA, Avery P, Monkhouse L, King BP, Wood P, Kesteven P, Daly AK, Kamali F: The impact of CYP2C9 and VKORC1 genetic polymorphism and patient characteristics upon warfarin dose requirements: proposal for a new dosing regimen. Blood 2005, 106:2329-2333.

8. Tham LS, Goh BC, Nafziger A, Guo JY, Wang LZ, Soong R, Lee SC: A warfarin-dosing model in Asians that uses single-nucleotide polymorphisms in vitamin $\mathrm{K}$ epoxide reductase complex and cytochrome P450 2C9. Clin Pharmacol Ther 2006, 80:346-355.

9. Lamba JK, Lin YS, Schuetz EG, Thummel KE: Genetic contribution to variable human CYP3A-mediated metabolism. Adv Drug Deliv Rev 2002, 54:1271-1294.

10. Barry A, Levine M: A systematic review of the effect of CYP3A5 genotype on the apparent oral clearance of tacrolimus in renal transplant recipients. Ther Drug Monit 2010, 32:708-714.

11. Kuehl P, Zhang J, Lin Y, Lamba J, Assem M, Schuetz J, Watkins PB, Daly A, Wrighton SA, Hall SD, Maurel P, Relling M, Brimer C, Yasuda K, Venkataramanan R, Strom S, Thummel K, Boguski MS, Schuetz E: Sequence diversity in CYP3A promoters and characterization of the genetic basis of polymorphic CYP3A5 expression. Nat Genet 2001, 27:383-391.

12. Kurose K, Sugiyama E, Saito Y: Population differences in major functional polymorphisms of pharmacokinetics/pharmacodynamics-related genes in Eastern Asians and Europeans: implications in the clinical trials for novel drug development. Drug Metab Pharmacokinet 2012, 27:9-54.

13. Miller SA, Dykes DD, Polesky HF: A simple salting out procedure for extracting DNA from human nucleated cells. Nucleic Acids Res 1988, 16:1215.

14. Montes R, Ruiz de Gaona E, Martinez-Gonzalez MA, Alberca I, Hermida J: The c. $-1639 \mathrm{G}>$ A polymorphism of the VKORC1 gene is a major determinant of the response to acenocoumarol in anticoagulated patients. Br J Haematol 2006, 133:183-187.

15. Bae JW, Kim HK, Kim JH, Yang SI, Kim MJ, Jang CG, Park YS, Lee SY: Allele and genotype frequencies of CYP2C9 in a Korean population. $\mathrm{Br} J \mathrm{Clin}$ Pharmacol 2005, 60:418-422.

16. Katsakiori PF, Papapetrou EP, Goumenos DS, Nikiforidis GC, Flordellis CS: Tacrolimus and 3-hydroxy-3-methylglutaryl-coenzyme A reductase inhibitors: An interaction study in CYP3A5 non-expressors, renal transplant recipients. Indian J Pharmacol 2011, 43:385-388.

17. Arvanitidis K, Ragia G, lordanidou M, Kyriaki S, Xanthi A, Tavridou A, Manolopoulos VG: Genetic polymorphisms of drug-metabolizing enzymes CYP2D6, CYP2C9, CYP2C19 and CYP3A5 in the Greek population. Fundam Clin Pharmacol 2007, 21:419-426.

18. Scott SA, Edelmann L, Kornreich R, Desnick RJ: Warfarin pharmacogenetics: CYP2C9 and VKORC1 genotypes predict different sensitivity and resistance frequencies in the Ashkenazi and Sephardi Jewish populations. Am J Hum Genet 2008, 82:495-500.

19. Scordo MG, Pengo V, Spina E, Dahl ML, Gusella M, Padrini R: Influence of CYP2C9 and CYP2C19 genetic polymorphisms on warfarin maintenance dose and metabolic clearance. Clin Pharmacol Ther 2002, 72:702-710.

20. Jorgensen AL, FitzGerald RJ, Oyee J, Pirmohamed M, Williamson PR: Influence of CYP2C9 and VKORC1 on patient response to warfarin: a systematic review and meta-analysis. PLoS One 2012, 7:e44064. 
21. Limdi NA, Wadelius M, Cavallari L, Eriksson N, Crawford DC, Lee MT, Chen $\mathrm{CH}$, Motsinger-Reif A, Sagreiya H, Liu N, Wu AH, Gage BF, Jorgensen A, Pirmohamed M, Shin JG, Suarez-Kurtz G, Kimmel SE, Johnson JA, Klein TE, Wagner MJ, International Warfarin Pharmacogenetics Consortium: Warfarin pharmacogenetics: a single VKORC1 polymorphism is predictive of dose across 3 racial groups. Blood 2010, 115:3827-3834.

22. Tavridou A, Petridis I, Vasileiadis M, Ragia G, Heliopoulos I, Vargemezis V, Manolopoulos VG: Association of VKORC1-1639 G > A polymorphism with carotid intima-media thickness in type 2 diabetes mellitus. Diabetes Res Clin Pract 2011, 94:236-241.

doi:10.1186/1756-0500-7-123

Cite this article as: Hadjipanagi et al:: Genetic polymorphisms in warfarin and tacrolimus-related genes VKORC1, CYP2C9 and CYP3A5 in the Greek-Cypriot population. BMC Research Notes 2014 7:123.

\section{Submit your next manuscript to BioMed Central and take full advantage of:}

- Convenient online submission

- Thorough peer review

- No space constraints or color figure charges

- Immediate publication on acceptance

- Inclusion in PubMed, CAS, Scopus and Google Scholar

- Research which is freely available for redistribution 